\title{
Study on the Development Mode of Xinjiang Lop Nur Human Intangible Cultural Heritage of Diet Culture Tourism
}

\author{
Nurbiye kamil $^{1, \text { a }}$, Xiaoling $\mathrm{Yu}^{1, \mathrm{~b}}$ \\ ${ }^{12}$ College of economics and Management ,Tarim University, Xinjiang, 843300 \\ ${ }^{a}$ email, ${ }^{b}$ email
}

Keywords: Xinjiang; Lop Nur Human; Food Culture; Tourism Development

\begin{abstract}
Tourism development of intangible cultural heritage is an important current concern of our cultural heritage and tourism development, because different types of non-material cultural heritage has a different connotation and bearer form, which is used in different areas to promote local tourism development among the development of tourism has a very important significance in promoting. From the point of view of tourism products constituted, it is nothing less than food, housing, travel, transportation, entertainment, shopping, rather than material cultural heritage tourism development is the intangible cultural heritage through a variety of packaging and combined into six tourism products. Xinjiang lop are profound food culture, has a very strong national geographical and cultural characteristics, to Rob's diet used in the development of tourism and cultural development of Xinjiang them, will have a very important role in promoting the development of tourism in Xinjiang, this article focused Xinjiang lop's diet culture and tourism development were studied, hoping to promote the development of tourism in Xinjiang tourism development through food culture. At the same time, we also hope that through this research can provide reference and recommendations for tourism development and Lop Human food culture has a similar situation in ethnic areas.
\end{abstract}

\section{Introduction}

Introduction: In China Lop Nur region, fishing for a living to live in a group of indigenous people Lop Nur, which we call "Rob people." Rob isolated for thousands of years people in the history of the formation of a person's unique ethnic Rob regional culture, they Hazel in the desert side of the fishing and hunting, planting crops, maintaining relatively primitive customs, their lives full of mystery and unique color. Now, with the deepening of the western development, each region of Xinjiang have made great progress, living in the Lop Nur area also became known, their cultural practices attracted the attention of many foreign tourists. Lop people who diet culture as one of the most representative of the cultural significance, its historicity, uniqueness and richness of features for promoting the development of Xinjiang tourism industry will have a very important role, so this paper for Lop Human food culture and tourism development model has been studied, hoping to push people into Rob spread of culture and promote the development of Xinjiang tourism.

\section{Lop Human Food Culture Features}

Xinjiang cultural connotation Rob's diet is extremely rich, it contains not only material factors, but also including human factors, including not only the material aspects of content, also contain spiritual connotations. Rob on the specific characteristics of the human diet in terms of culture, which is mainly manifested in the following aspects:

Lop Human food culture can be traced back seventeen thousand years ago in the Stone Age, after thousands of years of historical changes, Rob people with their industrious hands to develop a single person belonging to Rob's food culture. In the thousands of years of development, become a man Lop now to fishing for a living cultural practices, they created a unique food culture. All in all, Lop Human food culture, is in the thousands of millions of years to form precipitate which constantly advanced rich and diverse food culture Lop who has a long history of historic. 
Lop Human food culture in the precipitation of thousands, which not only has historical source far, also has a distinctive richness, which is mainly manifested in the type of diet and spiritual content diversity. Lop on the current terms of the types of people eating, which are divided into grilled, boiled type, pasta and cooking classes and other food categories. These different types of food now constitute the human diet Lop cultural diversity, and the ability to meet the different tastes of foreign tourists, much different foreign tourists.

Over the years, very few people with Lop and from the outside world, though rich in food culture, but little known to outsiders, it will be limited to the food culture surrounding Lop Nur, also formed today's unique regional characteristics and rich food culture Lop Human Lop Human unique food culture will be Lop spiritual culture into the diet, not only reflect the unique nature of the food, but also reflects the unique nature of the national culture, and it is this unique feature, attracting numerous for foreign tourists yearning Lop Human food culture.

\section{Typical Diet of Lop Human Culture}

Grilled fish is one of the most unique snack Lop Human. Lop Nur is located in the lower reaches of the Tarim River, has a rich variety of fish, fish salvaged Lop Nur will make a variety of things, fish is one of the most unique one, Lop people in Xinjiang unique red fish kebabs up grilled, so grilled fish both delicious river fish, there are tamarisk fragrance, people eat food for thought. Lop foreign tourists who eat this unique fish, both people feel Lop unique food culture, people can feel Lop's food culture with nature spirits.

Speaking of Xinjiang, many people will think of roasted whole lamb, roast whole human diet is one of the indispensable Lop, Lop always dedicated to Kaoquan most distinguished guests, roast whole and therefore also a guest on It represents a symbol of respect. Tarim River in Xinjiang, a large number of students in this growth Apocynum and Cistanche hay and other precious herbs, these grasslands fed out delicious and nutritious meat quality, Lop Human chosen two years old fat lamb as a main ingredient, plus Lop Human's unique way of barbecue, baked sheep taste unique and highly nutritional value, and therefore, people roast whole Lop widely sought after by foreign tourists.

Xinjiang perennial drought, food should not be stored for a long, so Uighur Uighur residents in long-term development of food culture invented Nang, Nang are portable, long-term storage, not bad, not moldy and nutritious characteristics, very Xinjiang diet culture. Lop people often Nang breakfast and tea-based, and sometimes dinner as well. Lop is one of the most famous small oil Nang. Small oil Nang good selection of raw materials, the Lop Nur area of quality wheat flour, milk, cottonseed oil, eggs, nuts, sheep tail oil and traditional baking powder, etc., taste delicious, even by tourists.

Uighur cornmeal porridge is "Wu Mashi", it is one of the main pasta Uygur. Lop cornmeal porridge very human person characteristic Lop will cut into pieces with the bones of ancient Qiama lamb and slice into the soup, and then gradually release such as cornmeal, stirring constantly with chopsticks placed in the process until the appropriate concentration when stopped into cornmeal, cornmeal porridge to cook for ten minutes until fully cooked. Lop brewed out such people especially porridge easy to digest, and colored flavor and taste, can increase appetite, lowering blood pressure, blood fat, eaten tourists are full of praise.

In addition to Lop who specializes in grilled fish with tamarisk, but also very good at barbecue with tamarisk, tamarisk barbecue Lop Human is unique. Lop usually chosen about two years old Jie diced lamb, marinated and then string tasty barbecue prod tamarisk on the barbecue grill Lop Human has two ways, one is to stand in the Nang pit barbecue skewers, grill it way one can bake a dozen series, so the taste of barbecue grill out fresh and delicious; another way is to grill skewers on the barbecue grill stove flip in when baked into a variety of spices, baked so old unique barbecue flavor, very Lop nor people food specialties. Today, people barbecue because of Lop population and unique taste is widely popular with visitors and Xinjiang has become a major tourist culture. 


\section{Development Model Conception of Lop Human Food Culture Tourism}

Lop has been people living in remote areas of our country, has been in the agricultural economy as the main man Lop income, resulting in the concept of man Lop too traditional, more exclusive foreign culture. To Develop Traditional and contemporary food culture tourism, the primary task is to change the traditional ideas Lop nor people, establish a modern concept, the courage to accept foreign culture and strive to Lop Human culture into the tourism development in Xinjiang them. Therefore, governments at all levels should pay attention to guide Lop Xinjiang people to change the traditional ideas, guide Lop who use their own national culture as a tourist development of content, will guide Lop Lop Human food culture as a tourist development content. So Lop will guide their own unique food culture as a tourist business projects, for their own minority culture can achieve Lai economic zone, but also to better promote itself Lop nur people food culture, better preservation of our country.

To develop the tourism industry, a region, the region will inevitably need to increase tourism projects in advocacy work, and the best publicity than build strong tourism brand. Thus, the Xinjiang government guidance Lop nor led people to use their own unique food culture, establish a unique food culture people Lop brand, attract more tourists to the Lop Nur area Recreational tourism. For example, carried out continuously in important urban and rural neighborhoods types of food cooking contest, such as roast game, playing Nang competitions; a group of various types of diet and cultural activities, such as roast whole campfire, fish tasting activities; can also organize a Lop Nur in Xinjiang Food culture Tourism Festival. In short, through this form of constructing food culture brand, not only to the people Lop food culture has attracted more visitors, have to better establish Lop people food culture brand for the future development of the tourism industry in Xinjiang indeed has a very important role in promoting.

In recent years, in order to enhance the quality of local tourism services, government straighten out a number of travel agencies, also organized many guides, tour operator and tourism statistics personnel training activities, also scenic spots have been upgrading and transformation, but the Lop Nur area of tourism market still does not seem mature dog, tourism service infrastructure is still not perfect, about food culture tourism service facilities are particularly lacking. Therefore, the Government should actively guide the cultural brand foodservice operators to do the work, from catering Construction, Decoration reflects Lop Human unique food culture atmosphere, text, music, pictures and other forms show the unique cultural characteristics Lop Human, guide the restaurant this positive business established national cultural Association diet, the founder of the catering industry chain and set up Special diet neighborhoods, etc., so perfect human diet Lop cultural tourism services, while promoting tourism to promote local economic development, but also better preserved Lop food culture.

Lop local people mostly catering management is more traditional family business model, this business model in the highly competitive restaurant market which is often compared because of a lack of scientific and effective management, marketing tools, so that people dining Lop difficult to diverse flavors on the market, grade complete Western fast-food restaurants, all kinds of hot pot restaurants compete. So, you want in the fierce competition in the market catering to win, the government should guide Lop who break the traditional pattern of decentralized, centralized multi Lop people food culture resources, Lop distinctive types of people gathered in a restaurant, some, such as actively set national snacks a street tourism street, making it the key development projects of local tourism, so visitors can not only make people focus on diet flavor savor Lop, Lop feel human culture, to better promote the development of local tourism for restaurant operators bring real economic benefits.

\section{Conclusion}

In a word, as one of the most representative characteristics of food culture in Xinjiang, Lop Human food culture gradually condensed in the long historical development and become our precious intangible cultural heritage. In the tourism industry continues to thrive today, Lop has historical 
human diet, rich, unique features, the development of Xinjiang to promote the tourism industry will have a very important role, so we should guide people Lop change ideas, explore new ideas, based on local, long-term perspective, and actively build Lop Human food culture tourism brand, the implementation guide Lop who formed food culture tourism idea of constructing a unique Lop Human food culture brand, strengthen infrastructure construction food culture tourism and services and is concentrating Lop multi-person food culture tourism resources development, really promote the rapid development of tourism in Xinjiang.

\section{Acknowledgements}

National Science and Technology Support Program, Tarim Intangible Cultural Heritage Integrated Service System and Applications.

Project No. 2013BAH27F04.

\section{References}

[1] Luo Boyan, Zhang Yingping. National Development and Yili Food Culture Tourism Resources Kazakh Example [J]. Chinese commerce .2009, (11).

[2] Maimaitizunong Abdukirim, Gan Guiqin, Abulimiti Adilijiang. Force Métis Kashgar Uyghur traditional food culture and tourism development [J]. Journal of Xinjiang University (Philosophy • Humanities and Social Sciences). 2011, (03).

[3] Zhang Yingpin. Development of Ili Kazak traditional food culture tourism resources [J]. Urumqi Vocational University [J]. .2008, (01).

[4] Wang Zesheng, Yi Yuanbin. Xinjiang Ethnic Food Culture Development [J]. Sichuan Higher Institute of Cuisine .2011, (05).

[5] Zhao Jin. On the spread of food culture and identity in Xinjiang [J]. World news .2015, (10).

[6] Rebiya wood, Aini Weyl, Wali Shah mention Pavan. Investigation of Lop Nur in Xinjiang Uighur folk food culture [J]. Science Article .2015 (02).

[7] Zhang Hao. Uygur food culture to explore. [J]. Tourism Monthly overview. 2014, (05). 